\title{
Muse, el latido de nuestra sociedad. Análisis de los videoclips Unsustainable + Isolated system
}

Muse, the heartbeat of our society. Analysis of Unsustainable + Isolated system video clips

\author{
Miguel Ángel Rivas Romero \\ ${ }^{1}$ Departamento Historia del Arte, Universidad de Málaga, España (mabusla@ @otmail.com)
}

Recibido el 21 de Diciembre de 2016; revisado el 12 de Enero de 2016; aceptado el 21 de Enero de 2017; publicado el 1 de Marzo de 2017

RESUMEN: Desde los estudios de la cultura visual se procede al análisis de los videoclips Unsustainable e Isolated System producidos por la banda de rock inglesa Muse para su sexto álbum de estudio The 2nd Law (2012). Además, se contextualizan de forma breve estas dos producciones audiovisuales tanto con el conjunto de la obra del grupo como con el momento político, social, económico y tecnológico con el que se relacionan.

PALABRAS CLAVE: Muse, Videoclip, Rock, Termodinámica, Insostenible, Sistema aislado.

\begin{abstract}
From the studies of the visual culture we proceed to the analysis of the video clips Unsustainable and Isolated System produced by the English rock band Muse for his sixth studio album The 2nd Law (2012). In addition, these two audiovisual productions are briefly contextualized both with the group's work as a whole and with the political, social, economic and technological moments with which they relate.
\end{abstract}

KEYWORDS: Muse, Videoclip, Rock, Thermodynamics, Unsustainable, Isolated system.

En el año 2008 comienza la crisis económica mundial: la Gran Recesión. El aumento del desempleo y la pérdida de derechos sociales desencadenaron numerosas movilizaciones ciudadanas a nivel mundial. Estas expresiones democráticas fueron reprimidas, mediante el uso de la fuerza, por gobiernos que protegían a los causantes de la crisis en detrimento de la ciudadanía. Esta realidad social en la que estuvimos y seguimos estando inmersos se ha visto reflejada en las diferentes disciplinas artísticas, en las de marcado carácter reivindicativo pero también, y debido a la magnitud del fenómeno, en los medios de masas.

Aunque no debemos olvidar que la función principal de los videoclips es servir como soportes publicitarios de los reclamos consumistas producidos por la industria discográfica, tampoco debe olvidarse la facultad instrumental de los videoclips, en cuanto vehículos de autoafirmación y/o propaganda para variopintos segmentos sociales y movimientos que han venido alentando su génesis y definición en calidad de testimonio documental -ya sea expositivo, contestatario y proselitista- de 
un código ético y una precisa declaración de intenciones que llevaría implícita una forma determinada de vivir, comportarse, actuar y pensar, convirtiéndolos, consecuentemente, en documentos antropológicos polivalentes, contradictorios y versátiles (Sánchez y García, 2009, p.7).

\section{Children of the Digital Revolution}

Numerosos artistas en diferentes medios, desde la fotografía al videoarte, desde la literatura hasta el cine, sin olvidar las series que están viviendo una nueva "Edad de Oro", están reflexionando sobre cómo la tecnología está transformando nuestras relaciones, la visión que tenemos del mundo, de los otros, así como de nosotros mismos. Si la fábula romántica propuesta por la película Her (Spike Jonze, 2014) nos muestra la imposibilidad de una relación entre un hombre y un sistema operativo, aunque posea la sensual voz de la actriz Scarlett Johansson, la serie británica Black Mirror (Charlie Brooker, 2011- ), se manifiesta como un espejo de fantasmas, donde se reflejan nuestros deseos pero también nuestras inquietudes, surgidas de estas nuevas interacciones de los individuos con la tecnología, evidenciando cómo éstas afectan a nuestras vidas, sacando a veces lo peor de nosotros mismos: ese monstruo, ese durmiente Mr. Hyde.

Sirva de ejemplo la banda inglesa de rock Muse, cuyo nombre es un fiel reflejo de la intencionalidad artística y estética de sus integrantes. Su producción artística, que comenzó a mediados de la década de los noventa del pasado siglo, está compuesta por siete álbumes de estudio: Showbiz (1999), Origin of Symmetry (2001), Absolution (2003), Black Holes and Revelations (2006), The Resistance (2009), The 2nd Law (2012) y Drones (2015). En sus letras se traducen sus inquietudes respecto a: conspiraciones globales, las revoluciones civiles, la ciencia en general y la astrofísica en particular, la tecnología y el ser humano, la búsqueda de vida extraterrestre, la economía, el pensamiento humano, el cambio climático y el miedo al fin del mundo. Pero será en sus directos donde el grupo mejor exprese su propuesta artística. Buena muestra de ello son sus tres excelentes álbumes grabados en directo Hullabaloo Soundtrack (2002), HAARP (2008), y Live at Rome Olympic Stadium (2013).

En ellos podremos disfrutar no solo del sonido de una de las bandas más reconocidas del momento, sino del cuidado con el que la banda diseña todo un despliegue mediático que abarca desde los instrumentos, -muestra de ello podrían ser las guitarras diseñadas por Bellamy junto al luthier inglés Hugh Manson o el piano transparente con luces en el interior que suelen utilizar en su magnífica versión del clásico Feeling Good (Anthony Newley y Leslie Bricusse, 1964)-, hasta unos escenarios y efectos que continúan la senda de luz marcada por bandas como Pink Floyd. Sus conciertos son videoclips en directo y sus videoclips son textos audiovisuales conformados por poéticas electrónicas propias de la cultura pop, animales culturales híbridos, hijos mestizos del videoarte de los años sesenta y de los videojuegos de los ochenta, nietos de las vanguardias históricas, que habitan en la jungla digital de nuestro paisaje cultural posmoderno.

Esta es una de las razones por las cuales los estudios de cultura visual no pueden permanecer ajenos a las propuestas artísticas de Muse, así que, por su concepción de la música como un arte total y su estrecha relación con la realidad social de nuestro tiempo, parece quedar justificado el análisis de 
una de sus creaciones audiovisuales más interesantes. Los videoclips, Unsustainable e Isolated system, fueron producidos por Muse y dirigidos por Tom Kirk para las dos canciones instrumentales que cierran su sexto disco de estudio: The 2nd Law (2012).

El primero de ellos huye de la narratividad para proponer un mensaje discontinuo y abierto, presentando los rasgos formales propios del videoclip, como son la heterogeneidad y la ultrafragmentación, donde "[...] la duración del plano viene determinada, no por la acción (como sería habitual en un régimen clásico de escritura), sino por las variaciones rítmicas o melódicas del tema musical que sirve de base" (Sedeño, 2009, p. 29). Por otro lado, el segundo destaca por el uso de un lenguaje audiovisual más próximo al régimen clásico, acercándose a mecanismos narrativos fílmicos, donde la música pierde protagonismo diegético y el plano se entiende como unidad espacio-temporal conceptual, y no como suele ocurrir en la mayoría de los videoclips donde la transición entre planos se impone sobre el contenido de los mismos. Por tanto, ambos casos ejemplifican las múltiples posibilidades formales que ofrece el medio, siendo por un lado, Unsustainable de tipo conceptual y, por el otro, Isolated system narrativo o dramático, por lo que resulta necesario su análisis conjunto.

Al comienzo del videoclip Unsustainable (2012) [1], gracias al frenético montaje de imágenes, determinado por la sincronía estética entre el tema musical y su discurso icónico, asistimos como espectadores impasibles a un bombardeo visual que nos muestra la caída de un sistema económico basado en un crecimiento continuo; mientras los recursos energéticos disminuyen exponencialmente. Escuchamos y vemos cómo una presentadora de un programa de informativos relaciona los sucesos económicos, políticos, tecnológicos y sociales con la segunda ley de la termodinámica. La conclusión a estos argumentos la establecerá, a modo de estribillo, un robot que repite el título del videoclip, mientras vemos algunas imágenes de los miembros de la banda tocando sus instrumentos. Este personaje cibernético nos llega incluso a decir que somos insostenibles, refiriéndose a que nuestra especie está condenada a la extinción. La música que acompaña a las imágenes es un tema instrumental que se abre con unos violines acompañados por un coro de voces. La aparente "serenidad" se rompe en el estribillo con una parte dubstep grabada con instrumentos analóigicos. La ausencia de un tema musical con letra y voz establece un marco de libertad que posibilita el despliegue de todos los rasgos definitorios de una estética propia del videoclip: preferencia por las imágenes impactantes y dinámicas, dando como resultado una gran saturación visual; sincronía entre música e imagen conseguida por medio del montaje; ritmo físico e interno acelerado; fragmentación de planos; discontinuidad temporal mediante el predominio de la elipsis; cambios de altura, escala, ángulo y nivel de planos; estética cromática vinculada con la psicodelia y el pop, mediante el uso de luces intensas y colores saturados; movimientos de cámara rápidos y bruscos...(García, 2009). En Unsustainable, la huida desenfrenada de la humanidad para escapar de la destrucción se escenifica con un grupo de personas corriendo a través un bosque, una huida hacia lo salvaje, hacia la madre Naturaleza: en este punto, el director del videoclip establece un nexo de unión narrativo con el siguiente videoclip, titulado Isolated system.

Isolated system (2012) supone el cierre musical del sexto álbum de la banda; su videoclip [2], comienza donde termina el anterior; un grupo de hombres y mujeres continúan su carrera huyendo del aumento de la entropía producida en el sistema aislado. Poco a poco, la entropía, representada como una ola digital, engulle todo a su paso, tanto objetos como personas. Mientras esto ocurre, vemos cómo el entorno del bosque da paso a un complejo industrial, abandonado junto a la playa. El número de 
corredores, víctimas de la entropía, va disminuyendo progresivamente. La escena final tendrá lugar en la playa, donde una joven, la última superviviente de la especie humana, corre por la arena huyendo de su extinción. Incomprensiblemente, ella se detiene, se gira y emprende una nueva carrera hacia la aniquilación. Como representante de toda la raza humana, esta moderna "Eva" no acepta su apocalíptico final con resignación, apostando por morir luchando. Estas imágenes finales se apoyan sobre una base instrumental con el piano como protagonista, mientras las voces de los informativos repiten a modo de macabra letanía la frase derivada de la segunda ley de la termodinámica: “en un sistema aislado, la entropía sólo puede aumentar".

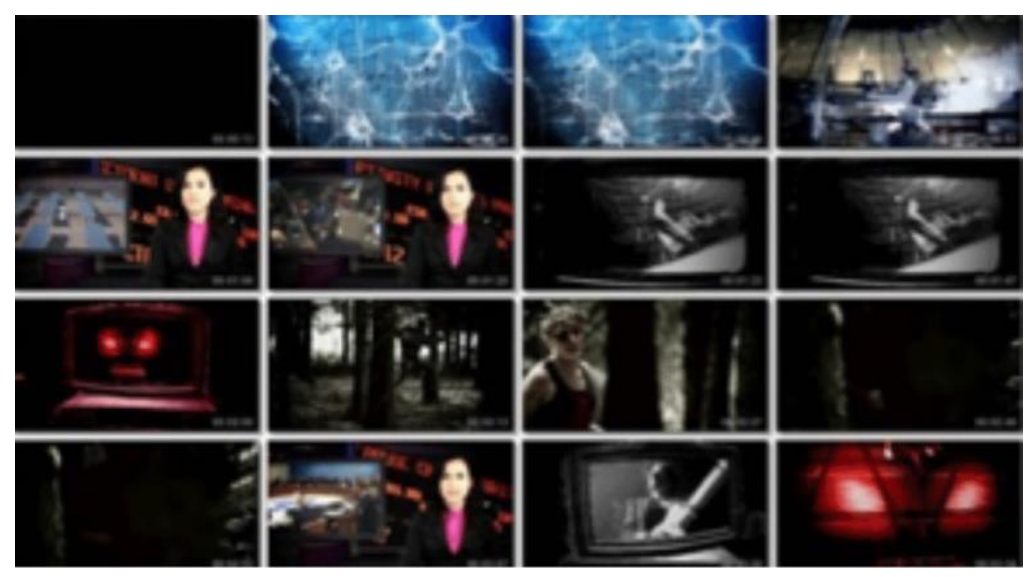

1. Fotogramas del videoclip Unsustainable.

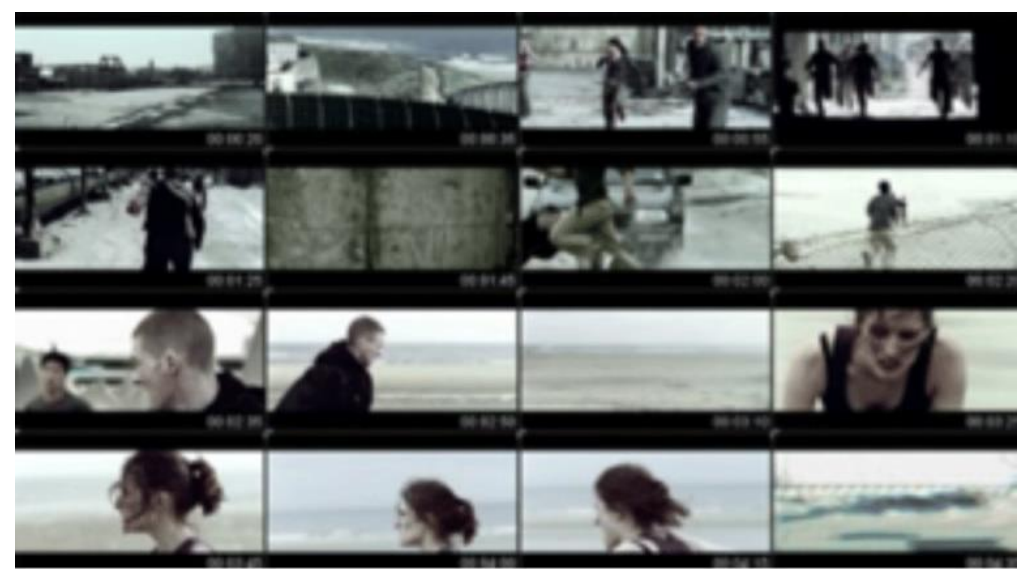

2. Fotogramas del videoclip Isolated system.

\section{Conclusiones}

En definitiva, la producción artística de Muse es un fiel reflejo de la sociedad global, capitalista y tecnológica en la que estamos inmersos. A diferencia de otras manifestaciones artísticas, las canciones de Muse no están circunscritas a un ámbito social ni geográfico delimitado. Internet ha permitido la creación de obras de arte con una representatividad geográfica, social y cultural sin precedentes. Además, debido al proceso de globalización, que no sólo afecta a los países desarrollados, nuestros 
problemas son compartidos, con independencia de raza, cultura, idioma, religión, procedencia o ideología. Unsustainable e Isolated system, se postulan como dos Imago Musicae que, mediante el empleo del experimentalismo plástico propio de su medio, plasman nuestras inquietudes ante los momentos de suma inestabilidad que seguimos viviendo. El propio Matt Bellamy, líder del grupo, reconoce que las canciones están inspiradas en un informativo real, en el cual se relacionaba la crisis con las leyes físicas. Luego, la realidad social de una época es filtrada por la mente del artista y plasmada en una obra multimedia, que a su vez, es proyectada hacia esa misma sociedad, utilizando los medios tecnológicos apoyados en el sistema financiero causante del problema. Aparentemente, el artista, solo ha reelaborado una información con intencionalidad estética, pero en realidad ha conseguido mucho más, introducir en el sistema aislado una variable muy importante: la posibilidad del cambio. No podemos negar que nuestra sociedad vive sumida en el desconcierto provocado por un sistema económico insostenible, pero tampoco podemos obviar la respuesta social mundial pidiendo un cambio. Las movilizaciones sociales, representadas en el segundo videoclip por la mujer que se enfrenta contra nuestro destino, son un rayo de esperanza. La sociedad y el artista piensan que necesitamos un cambio que suponga una mejora de la calidad de vida de toda nuestra especie. El sonido que Muse elige como representativo de esa esperanza, con el que se cierra el tema y el disco, no es otro que los latidos del corazón, en su vientre materno, del futuro hijo del cantante, compositor y guitarrista del grupo, Matt Bellamy: el latido de nuestra sociedad.

\section{Referencias bibliográficas}

GARCÍA GÓMEZ, Francisco (2009), "El hijo marchoso del cine: Relaciones e interdependencias entre el cine y el videoclip", en SÁNCHEZ LÓPEZ, Juan Antonio y GARCÍA Francisco (coords.), Historia, Estética e Iconografía del videoclip musical, pp.43-142, Servicio de publicaciones de la Universidad de Málaga, Málaga.

SÁNCHEZ LÓPEZ, Juan Antonio y GARCÍA GÓMEZ, Francisco (2009), “Introducción. Reflexiones para después de un seminario", en SÁNCHEZ LÓPEZ, Juan Antonio y GARCÍA, Francisco (coords.), Historia, Estética e Iconografía del videoclip musical, pp.7-16, Servicio de publicaciones de la Universidad de Málaga, Málaga.

SEDEÑO, Ana María (2009), "El videoclip musical en el contexto del lenguaje musical en el contexto del lenguaje audiovisual", en SÁNCHEZ LÓPEZ, Juan Antonio y GARCÍA, Francisco (coords.), Historia, Estética e Iconografía del videoclip musical, pp.17-42, Servicio de publicaciones de la Universidad de Málaga, Málaga. 
